\title{
Potential consequences of the immigration ban on the scientific community
}

\author{
Hossein Ardehali \\ Feinberg Cardiovascular Research Institute, Northwestern University Feinberg School of Medicine, Chicago, Illinois, USA.
}

\begin{abstract}
On January 27, 2017, President Trump signed an executive order banning the citizens of 7 countries from obtaining US entry visas for the next 90 days. Since the announcement, the news media have devoted a large portion of their coverage to the ban and its political ramifications. There have been arguments made by both sides that the ban will make our country safer, while others have argued that this executive order will result in the weakening of our country and bolstering of our enemies. As a physicianscientist who was born in Iran and immigrated to the US, I will stay away from the politics of this executive order; rather, I want to discuss the impact of the immigration ban on scientific discourse, education, and research programs, and how it may influence the dissemination of knowledge to physicians and scientists in low- and middle-income countries. I will use my own experience as an example of how the educational and scientific systems in this country benefit those who strive to learn in a free and intellectually stimulating environment.
\end{abstract}

My father came to the US from Iran in 1948 through Ellis Island. After receiving his PhD from Clark University, he returned to Iran in 1953 and was employed through the US-sponsored Point Four program to help Iran financially and prevent communist expansion to the country. This program, along with others, kept Iran as a close US ally and free of communism for many years, demonstrating how the American education system can work to mutually benefit the citizens of both nations. Additionally, my parents, who highly valued education, sent my siblings and me to the US before we finished high school.

I immigrated to the US at the age of 16. Upon arrival, I found myself in an environment that I had never experienced before: an environment where every person is considered a human being with the full privileges of that condition; a society where one can learn from different creeds, discuss pertinent issues, and follow the principles that are most consistent with his or her beliefs. These personal experiences had a profound impact on me, encouraging me along my path in the pursuit of knowledge. Thus, after receiving my high school diploma and college degree, I applied to medical schools, and despite not having a green card, I was accepted to the Vanderbilt Medical Scientist Training Program and obtained my MD and PhD degrees in 1998. I am now a practicing cardiologist, a physician-scientist with $\mathrm{NIH}$-funded research, and a professor at Northwestern University in Chicago, Illinois.

Despite entering the country at the age of 16, I did not get my green card until 20 years later, and I ultimately became a US citizen 25 years after my arrival into the US. This delay in getting my citizenship was due to the tight immigration laws that regulate the path to US citizenship. These regulatory mechanisms are particularly cumbersome for an Iranian citizen, a country labeled by the US State Department as a state sponsor of terror- ism. Unlike my friends and classmates from other countries who traveled to their homeland freely, I had to obtain a new US visa in a third country (since there is no US Embassy in Iran) every time I left the country. In addition, I had to wait 3-4 weeks for security clearance, making travel outside of the US extremely difficult. Despite this hardship, I always considered myself a very fortunate individual for having the opportunity to reside in the US and benefit from its exceptional education program. After all, I did not only consider the US the greatest country in the world, but also one of the greatest and most hospitable societies in the history of mankind.

My story demonstrates that the sophisticated educational programs and the unbiased eye of the US education system towards the background of its students has benefited many young people who ended up staying in this country and has contributed to the medical and scientific advances in the US. The benefits are not limited to the individuals who immigrate to the US; they extend across generations, as demonstrated in my case with my father and now with my own children. We are a country of immigrants, and we are stronger when we open our doors wisely, but welcomingly. Never during my time as a non-US citizen did I feel that the vetting of my background was not held to the highest possible standard. The system applied to Iranians worked well, although in my view was not fair at times due to its exceedingly tight regulations.

Implementation of the Trump administration's travel ban will have many consequences, and its effect on the scientific community is not an exception. This ban will prevent bright students, scholars, and physicians from those seven countries from entering the US, and will display a hostile image of American education and science. American academics have historically been removed from politics to maintain their independence as an intellectually stimulating environment, a unique 
feature that does not exist in nondemocratic countries. Unfortunately, this ban will indirectly politicize, and thus weaken, the education system in the US. I acknowledge that some may disagree with this last statement and I wholeheartedly sympathize with such sentiment. But enacting policies that exclude scholars from countries that have a proven record of benefitting the US scientific system does not bode well for our country.

Another consequence of this ban is that physicians and scientists from those countries will be prevented from obtaining the most recent scientific advances. This barrier can potentially endanger the lives of mil- lions of innocent people - regular citizens who are not responsible for the actions of their governments. Science and medicine should not have borders. The dissemination of knowledge, without boundaries, is the ultimate goal of the scientific community.

The detrimental consequences of this ban on the scientific community will be significant and may affect many generations to come. My father was the first in his family to migrate to the US, and his pioneering move opened the path for so many after him to come to this country. The result has benefitted both Americans and Iranians and helped the US achieve its goals in the Middle East. As someone who has had firsthand experience from the tight immigration rules applied to Iranians, I can attest that the ban will have negative, and possibly grave, consequences. I am heartened by the recent federal court decisions providing a formal stay against the ban, but I urge the administration to reevaluate their decision and consider input from the scientific community while deliberating further actions.

Address correspondence to: Hossein Ardehali, Tarry 14-733, 303 E. Chicago Ave., Chicago, Illinois 60611, USA. Phone: 312.503.2342; E-mail: h-ardehali@ northwestern.edu. 